\title{
Adopting A New Hybrid Force Model: A Survey During Covid-19 In Indian Higher Education
}

\author{
https://doi.org/10.3991/ijet.v16i16.23371 \\ Ranjeeva Ranjan ${ }^{1}$, J. L. López ${ }^{1(\varpi)},{\text { Kanhaiya } \text { Lal }^{2} \text {, Suraj Saxena² }}^{2}$ Sanjeev Ranjan ${ }^{2}$ \\ ${ }^{1}$ Universidad Católica del Maule, Talca, Chile \\ ${ }^{2}$ Birla Institute of Technology, Mesra, India \\ jlopez@ucm.cl
}

\begin{abstract}
This quantitative study proposes and validates the Hybrid force model by analysing the challenges and opportunities in online education during COVID-19 through an online survey from students and teachers of Indian higher education institutions. The proposed model considers the learner as a system of study and talks about the amalgamation of knowledge, human force (teacher) and technological force for better online learning opportunities and experience. The results show Google Meet, Zoom and Microsoft Team as the main online platforms for imparting the classes while almost $80 \%$ of the students prefer a non-traditional teaching method (online and hybrid). The results highlight that more than $88 \%$ of the students prefer to have a personal teaching assistant in their learning trajectory.
\end{abstract}

Keywords- Hybrid force, technological tools, COVID-19, online education, Indian higher education, Chatbot.

\section{Introduction}

The pandemic created by COVID-19 has become one of the greatest challenges for the entire world in this century. Intending to stop the spread of this disease, countries turned physical distancing into the most massive non-pharmaceutical measure, which forced educational systems to discontinue the face-to-face classes, and to generate mitigation measures adjusting to national realities. According to UN (United Nations) News [1], one year into the COVID-19 pandemic, over 800 million students, more than half the world's student population, still face significant disruptions to their education, ranging from full school closures in 31 countries to reduced or part-time academic schedules in another 48 countries. The pandemic has led to substantial educational changes, including migration to virtual learning ecosystems. The health measures force teachers to move from face-to-face instruction delivery methods to primarily virtual and online platforms using 21st-century tools [2]. Teachers faced with the task of addressing a wide range of needs to ensure educational continuity for students.

It is a common fact that education today is no longer bound to the classroom settings but has taken a new shape in the form of the online mode of education in the 
entire world. During the pandemic, there has been a paradigm shift in the whole teaching-learning process at a global level and in the educational field, online education has gained a lot of momentum. All three stakeholders, teachers, students and policymakers, have their own glitches and problems to overcome while adopting this change. Within the online mode, the experts are trying to employ different artificial intelligence (AI) enabled technological tools to improve the pedagogical process for better learning experiences. The present study examines the impact of online technological tools used in the higher education institutions (HEIs) in India during the times of COVID-19 in general and AI application, in particular. This time of pandemic poses challenges to align the educational system to the new reality by evaluating the learning performance and experience with the help of technological tools and investigating the effectiveness of technology-based learning systems from various perspectives.

The COVID-19 pandemic has brought many challenges to higher education in terms of teaching, learning, research collaborations and institutional governance [3]. One of the areas of research in the field of online education is to examine and analyse the perspective of stakeholders involved in this process. The two main protagonists in the traditional instructional process are the learner and instructor (teacher). However, in online education, two more categorizations of stakeholders have been suggested which are designer and implementer [4]. Choudhury and Pattnaik in their study on the emerging themes in e-learning analysed 138 research studies in which 39 different models were found encompassing these four categorizations of stakeholders [4]. Another important aspect to be highlighted in this regard is considering the online pedagogic process as an interaction between both people and process [5], in which the learning occurs through constant negotiation between the social aspect of the stakeholders (learners and teachers) and magnitude of the technical force applied. In the present study, the researchers have tried to develop a model, which comprises the learner as the system on which various forces are applied. The model is referred to as a Hybrid force model, which is based on the amalgamation of knowledge, human force (teacher) and technological force for better online learning opportunities and experience. The model does not include the fourth stakeholder, which is the implementer. However, the third one, which is the designer, is present under the technological force but not explicitly mentioned in the model. It is in constant evolution and the instructors can make use of their content knowledge and modulate it with the help of technological force. This could help the instructors to carry out student-centred pedagogies with the assistance of educational technologies and change it according to the feedback after the evaluation and decision-making. For example, they can determine where to allocate time for the transformation of their courses by assessing the content roles, learner-focused pedagogies, and educational technologies [6].

Two important aspects of the proposed model are its cyclical nature and its constant evolution. The study aims to identify the important technological tools used in imparting classes in Higher Education in India during COVID-19 and examine them critically. The research further provides the Hybrid force model as explicated before and analyse the challenges and opportunities during the online education and implementation of technological tools in Indian universities. The study concludes that a 
hybrid education method would lead to better learning performance in the classroom, at the same time allow the use of the available technological tools, and suggest a great opportunity to implement this method with the characteristics proposed in the present research. This study is the first of its kind to propose the Hybrid model which includes the direct interaction between the human factor (professor), the knowledge (content) and the technology (technological tools). This model is a proposal based on a survey done in the HEIs of India and has not been tested in the practical classroom context.

\section{$1.1 \quad$ Objective}

Keeping in mind the above discussions, the main objectives of this research proposal are the followings:

a) To identify the important technological tools used in imparting classes in Higher Education in India during COVID-19 and examine critically these tools reported being used.

b) To propose the Hybrid force model applicable in the field of education based on simultaneous interaction between human, content and technological tools.

c) To identify the challenges and opportunities of implementation of these technological tools in universities in India during COVID-19. You may also simply delete all the text in this document, paste yours and format it with the styles.

\subsection{Research questions}

Following the objectives of the study, the present research seeks to answer the following research questions:

1. What are the important technological tools used in imparting classes in Higher Education in India during COVID-19?

2. Did the technological tools used during COVID-19 improve the academic performance of the learners of Higher Education in India?

3. What type of learning (standardized, collaborative and personalised) and mode of teaching (traditional and online) was preferred by the learners of Higher Education in India during the pandemic times?

4. What is the future of technological tools in the field of Higher education in India taking their help as a personalised guide?

\section{Review of literature}

Research in the field of Artificial Intelligence in Education (AIED) is being carried out in different parts of the world but in the Indian context, this effort has not been explored to its full potential. The pandemic has caused a paradigm shift in the pedagogic process wherein the different technological tools in online education are being used, but this process lacks a robust theoretical framework. Despite being a lack of 
research in this field, the literature review reveals that $\mathrm{AI}$ is highly incorporated in the Higher education system. University and colleges are highly dependent on AI-based tools to make learning interactive. AI tools and digital transformation in education has seen an enormous surge during this pandemic period worldwide [7]. Silander and Stigmar in [8] demonstrated AI and its expanded domain of new possibilities in the Education community in a developing country like India. Although India faced many issues due to sudden lockdown in the country due to COVID-19 and the Traditional Education System was disrupted [9], online education immediately came into effect. Aljawarneh [10] states the impact and benefits of various e-learning tools that utilize AI to enhance learning like Moodle, WEB 3.0 among others. Caliskan et al. [11] in their descriptive study regarding opinions of the teachers on technology and online education during pandemic highlighted the need for in-service teacher training. However, the study did not consider any theoretical framework to develop their work. Oktavianto et al. [12] in their study through Classroom Action Research (CAR) design reported the effectiveness of the blended learning integrated fieldwork as a learning model during the pandemic. They carried out their research in Indonesia on 32 secondary students in Geology. Almusharraf and Khahro [13] in their research evaluated the level of satisfaction with online learning platforms and learning experience amongst the 283 postsecondary students in Saudi Arabia. The results showed that Google Hangouts was the most effective tool for lecture delivery followed by Google Classroom and LMS (Moodle). The study also highlighted the students' satisfaction with overall online learning activities including the evaluation and technical support.

Popenici in [14] highlight that in the context of realization of applications of AI in higher education in India, one can interpret AI as computing systems capable of engaging in human-like processes such as adapting, learning, synthesizing, correcting and using various data required for processing complex tasks. There are approaches like [15] and [16] that proposes a collaborative learning method, which comprises of the Human-AI combination a hybrid framework for better adaptation in education and enhances learning. Students and teachers perception when merging AI with education was explored through a study conducted by [17], which was focused on implementation, evaluation and qualities of students. Chatterjee and Bhattacharjee in [18] carried out their research in the field of adoption of artificial intelligence in higher education by taking the help of many adoption theories and models including 'The Unified Theory of Acceptance and Use of Technology' (UTAUT) model [19]. They identified the determinants that would help and accelerate the adoption of AI in higher education. They found that Performance Expectancy (PE) has an insignificant impact on Attitude (ATT) thus causing hindrance in adopting the AI technology in higher education in India. In another study, [16] provided a conceptual framework for Human-AI Hybrid Adaptivity in education. They provided the below categories wherein possibilities exist between AI and Human both for augmenting performance and for co-learning.

- Goal Augmentation, (Informing Each Other's Instructional Goals)

- Perceptual Augmentation, (Leveraging Complementarity in Perception)

- Action Augmentation, (Leveraging Complementarity in Action Spaces)

- Decision Augmentation. (Leveraging Complementarity in Decision-Making) 
Zheng and $\mathrm{Li}$ in [20] used the technology acceptance model (TAM) to analyse the learners' intention to employ tablet computers in K12 settings. They proposed an extended TAM model with self-efficacy predicting students' perceived ease of use and perceived usefulness of tablet computers in K12 settings. Zawacki et al. in their systematic review reported that there is very little evidence for the advancement of pedagogical and psychological learning theories related to AI-driven educational technology [21]. They further added that the majority of research in their systematic review merely focused on analysing and finding patterns in data to develop models, and to make predictions that inform student and teacher facing applications. The lack of theory might be a syndrome within the field of educational technology in general. In a recent study, [22] found that more than $40 \%$ of articles in three top educational technology journals were wholly a-theoretical. Therefore, it is important not only to examine and analyse the various technological tools being used in the online pedagogic process and its impact on academic performance but also to come up with a theoretical model which could explain the underlying mechanisms. In this sense, the present research aims to provide a framework to explain the same.

\section{Research in the field of Higher education in India during COVID-19-19}

There have been a plethora of research studies reported during the pandemic and its impact on higher education in India. The majority of these studies are quantitative in nature and provides their results within the existing theoretical model of the online teaching-learning process. For example, [23] in their study with 222 university faculty members in India used the Unified Theory of Acceptance and Use of Technology (UTAUT) theoretical model. They introduced and validated through an online questionnaire survey, three new constructs which are facilitative leadership, regulatory support and project team capability. In another study, [24] explored the relationship between three constructs namely quality of learning experience (QLE), student satisfaction (SS) and perceived overall experience (POE). The study was done in the higher education institution with the undergraduate students and they found out a significant relationship between SS and POE. Syed et al. conducted a 3-week orientation program before the start of the semester and carried out a pre-and post-survey to examine the challenges faced by teaching faculty members and students due to the sudden switch to online learning [25]. They analysed the impact of the capacity building efforts on the teaching and learning process and discussed the implication of the results in the post COVID-19 world where blended learning would become the default mode of education in higher education. Sangwan et al. [26] in their research developed and validated an Attitude Scale towards Online Teaching and Learning for Higher Education Teachers with the participation of 687 faculty members from various colleges and universities of India. After conducting factor analysis, they came up with a 30 item questionnaire with four factors which are Appreciation for online teaching and learning (10 items), Responsiveness towards online education ( 7 items), Proficiency in handling online teaching (8 items) and Knowledge of technological 
reforms (5 items). Keeping these discussions in mind, the current research proposes a model with a holistic approach, which could respond to the theoretical understanding of the online teaching-learning process. Another important aspect of the research studies in the AIED is that the majority of the studies include the AI-Human interaction from the teacher and teaching perspective and sometimes lacks the learner and learning aspect. For this study, the learners are considered as principal part on which different forces are applied resulting in the learning outcome. The study proposes a Hybrid Force model, which has been described in the next section.

\section{$4 \quad$ Hybrid Force Model}

From the point of view of physical science and control engineering, the evolution and control of a system under study requires the presence of applied forces and the response of the system to the application of these forces. The evolution of the system depends directly on the forces applied along with their magnitude, the direction and the sense of each one of them. Likewise, in order to have a controlled evolution, each of the involved forces must be applied appropriately according to the response provided by the system each time it is subjected to evaluation. On the other hand, a teaching-learning model can be seen as a controlled and isolated system (external factors are not considered within the model: psychological, social, economic, etc.), whose dynamics can evolve favorably based on the applied forces and constant performance evaluations (feedback). Thus, thinking of a controlled teaching-learning model, based on a hybrid force (application of several forces) makes a lot of sense.

The proposed model considers the learner as the system of study, on which the following forces act:

a) Knowledge force.

b) Human force (teacher).

c) Technological force (digital tools - artificial intelligence).

In this model, the content or discipline to be taught is considered to be the force of knowledge, whether face-to-face and/or virtual. The force of knowledge must always be directed by the human force, where the teacher or pedagogical facilitator is in charge of channelling it (applying it appropriately) to reach a goal (objective of the course) and give meaning to the knowledge. Likewise, the application of a technological force, given the constant development and use of new digital tools and artificial intelligence, becomes indispensable for disseminating knowledge related to the discipline.

The existence of knowledge, teachers and technology would be of no importance, alone or together, if they are not applied to a system. Referring to the system under study, it is required to be equipped with technology (student with technological knowledge) and to give continuous feedback (information on academic performance, as a result of constant evaluation) to be able to properly adjust each of the applied forces in order to keep the system in constant evolution (control). 
Figure 1 schematizes the hybrid force model. The application can start by considering the equal magnitude of each of the forces that constitute the model, which in turn, generates acquired and measurable learning by the student. Based on the acquired learning, decisions are made to determine which forces should be modified or adjusted. In this model, the teaching process applied through the hybrid force and the response delivered in terms of the learning acquired by the student is constantly being evaluated and adjusted. In each cycle of the model, the teaching process must be adjusted in each of the forces (human with knowledge and technological) to achieve optimal and satisfactory performance. The dynamic interaction between the forces is considered part of the feedback in the sense of the adjustment and application of each of the considered forces and has not been dealt with separately. In the current study, the above model has been validated through the survey.

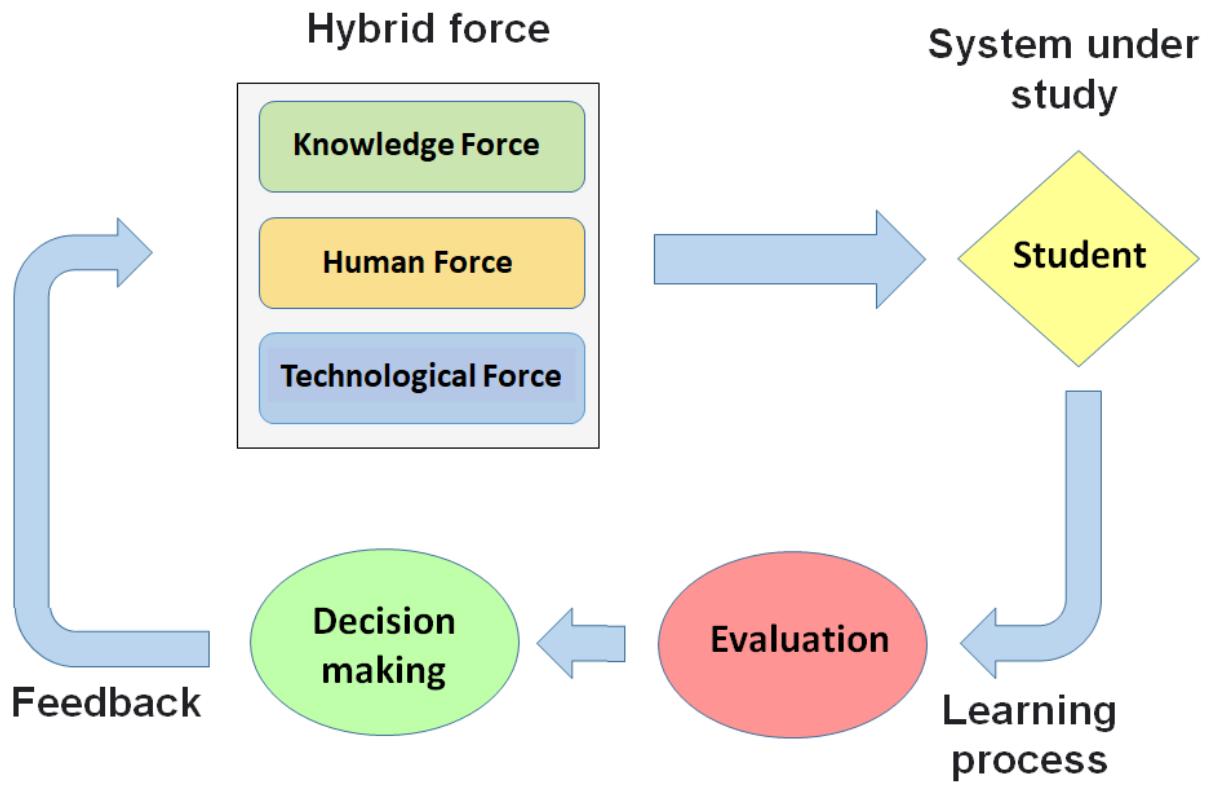

Fig. 1. Hybrid force model for higher education which is composed of three forces adjusted by continuous feedback and decision making.

\section{$5 \quad$ Methodology}

The present research is a quantitative, cross-sectional, descriptive and nonexperimental study type and the researchers have used an online questionnaire to know the opinion and perspective of learners and teachers as suggested by [27] who mention that surveying instructors' and students' attitudes toward e-learning is a critical issue in learning and training. The researchers have examined the self-reported questionnaire with statistical and interpretive analysis. 
A 16-set questionnaire was developed keeping in mind the two types of participants; students and teachers, which included a variety of multiple-choice, dichotomous questions, and two Likert scale questions. The survey was administered using the Google Forms platform, with complete anonymity without asking for their names or email accounts. The questionnaire was distribution with the help of emails and through social media platforms, and standard messaging services. The web-based survey was conducted to students through the medium of Google online platforms from December 1 to December 31, 2020.

The current study is quantitative research within the descriptive framework wherein the important online tools, including AI, instructional and assessment mode, which have been used during the pandemic situation, have been analysed and examined. The self-reported questionnaire was used to see the perspective of the students and teachers regarding their learning and teaching experience respectively. The questionnaire was prepared after a comprehensive review of the available literature. The questionnaire was sent to three experts from the educational field for their feedback and changes were made according to their observation. The questionnaire has been produced below in the tabular form.

The online survey questionnaire consisted of 3 parts:

a) In the first part, the participants had to provide their consent to use the responses of the survey only for academic purposes.

b) The second section contained the background information questionnaire (BIQ) of the participants. Participants were asked to provide information about their general demographics, such as age, gender, institute name, location, course etc., which were relevant for the study.

c) In the last part, the students' questionnaire consisted of 5 multiple choices, 5 dichotomous questions and 1 question with a Likert scale rating, whereas and the teachers' questionnaire comprises of 2 multiple choice and dichotomous questions and 1 question with Likert scale rating from 1 to 5 . The questions were analysed under three main themes; technological tools used in pandemic, tools to improve learning, mode and type of learning.

\subsection{Ethical consideration and data analysis}

The survey was carried out in a properly informed set up with clear instructions and consent form with the statement of the volunteer participation in the google form. Once the participants clicked on the consent form then only they were permitted to enter the survey. The ethical considerations, such as asking for permission and assurance of confidentiality, were taken care of throughout the research process. The data analysis was carried out with Python 3.7. In particular, the following combinations of software libraries were used:

1. Data manipulation : pandas 0.2.4, https://pandas.pydata.org/.

2. Data manipulation and statistical analysis: NumPy v1.20.0, https://numpy.org/.

3. Data Visualization: Matplotlib 3.3.3, https://matplotlib.org/. 


\subsection{Questionnaire}

Table 1. Students' questionnaire

\begin{tabular}{|c|c|c|}
\hline ID & Questions & Type of questions \\
\hline 1 & $\begin{array}{l}\text { What tools did your university use during immediate lockdown due to } \\
\text { COVID-19-19 to continue education? }\end{array}$ & Multiple choice \\
\hline 2 & $\begin{array}{l}\text { How do you rate the technological tools/applications, which your institu- } \\
\text { tion used during the Lockdown? }\end{array}$ & Likert scale rating 1-5 \\
\hline 3 & $\begin{array}{l}\text { Are you aware that the educational platform (Google Meet, MS Teams, } \\
\text { Zoom etc.) of your Institute is Artificial Intelligence (AI) driven? }\end{array}$ & Dichotomous (yes/no) \\
\hline 4 & Has the use of technological tools helped to improve your performance? & Dichotomous (yes/no) \\
\hline 5 & $\begin{array}{l}\text { Which one do you prefer the most: traditional, online or hybrid method of } \\
\text { carrying out the classes? }\end{array}$ & Multiple Choice \\
\hline 6 & If online, which mode of instruction do you prefer? & Multiple Choice \\
\hline 7 & $\begin{array}{l}\text { Which mode of assessment do you prefer: Online mode at home (conduct- } \\
\text { ed in an empty room with video and audio on) or traditional mode con- } \\
\text { ducted in the classroom? }\end{array}$ & Dichotomous \\
\hline 8 & $\begin{array}{l}\text { Would you like to have a teacher professor to assist you during your } \\
\text { work? }\end{array}$ & Dichotomous (yes/no) \\
\hline 9 & Do you know about Chatbot? If yes, then please answer the next question & Dichotomous (yes/no) \\
\hline 10 & Would you use a Chatbot as a teacher to assist you in your learning? & $\begin{array}{l}\text { Multiple Choice } \\
\text { (yes/no/maybe) }\end{array}$ \\
\hline 11 & $\begin{array}{l}\text { Taking into account the use of information technology, what type of } \ \\
\text { teaching do you prefer? }\end{array}$ & Multiple Choice \\
\hline
\end{tabular}

Table 2. Teachers' questionnaire

\begin{tabular}{|l|l|l|}
\hline ID & \multicolumn{1}{|c|}{ Questions } & \multicolumn{1}{|c|}{ Type of questions } \\
\hline 1 & $\begin{array}{l}\text { What tools did your university use for teaching during immediate lock- } \\
\text { down due to COVID-19-19? }\end{array}$ & Multiple choice \\
\hline 2 & $\begin{array}{l}\text { How do you rate the technological tools applications, which your institu- } \\
\text { tion used during the Lockdown? }\end{array}$ & Likert scale rating 1-5 \\
\hline 3 & $\begin{array}{l}\text { Are you aware that the educational platform of your Institute is Artificial } \\
\text { Intelligence (AI) driven? }\end{array}$ & Dichotomous (yes/no) \\
\hline 4 & $\begin{array}{l}\text { Which one do you prefer the most: traditional, online or hybrid method of } \\
\text { Il carrying out the classes? }\end{array}$ & Multiple Choice \\
\hline 5 & $\begin{array}{l}\text { Do you think the use of information technologies helps to improve the } \\
\text { learning \ performance of students? }\end{array}$ & Dichotomous (yes/no) \\
\hline
\end{tabular}

\section{Results and Discussion}

\subsection{Participants}

In the current study, a cross-sectional survey includes students and teachers from different higher education institutions in India. A summary of participants in the form of numbers and percentages is provided below. 
The age of the participants in the student category varies from 18 to 35 years $(\mathrm{M}=22.46, \mathrm{SD}=3.10)$ and in the case of teachers, it oscillates between 25 and 58 $(\mathrm{M}=40, \mathrm{SD}=8.21)$. The same is produced in Figure $2 \mathrm{a}$ (students) and Figure $2 \mathrm{~b}$ (teachers). With regard to gender, the participants in both categories have an equal percentage of male $(57 \%)$ and female $(43 \%)$ participation. The details of the participants from both groups are produced below in the tabular form. Table 3 shows the numbers of participants from the student category academic program and subject area wise. Table 4 shows the participants' department and gender from the teacher category. Table 5 shows the institution type and location of the participants from the teacher category.
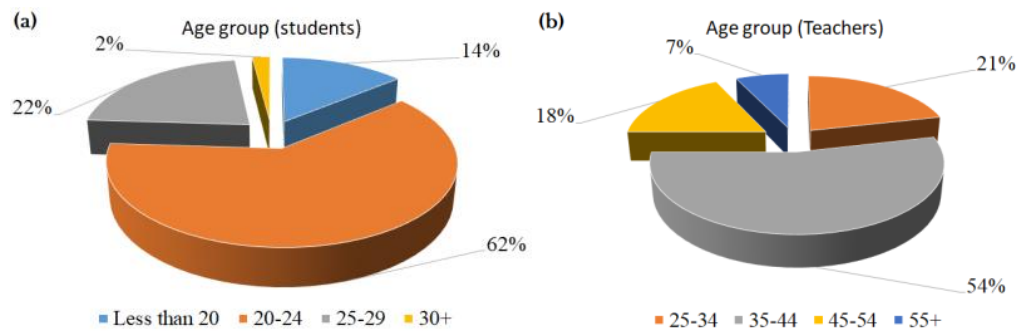

Fig. 2. Summary of participants in the current study for (a) students and (b) teachers, from different higher education institutions in India.

Table 3. Percentage of participants subject area and academic programme wise (students)

\begin{tabular}{|l|c|c|c|c|}
\hline Scabject area & Arts \& Humanities & Sciences & Social Sciences & Total \\
\hline Bachelors & $13 \%$ & $28 \%$ & $0 \%$ & $41 \%$ \\
\hline Masters & $5 \%$ & $12 \%$ & $13 \%$ & $30 \%$ \\
\hline PhD & $2 \%$ & $5 \%$ & $0 \%$ & $7 \%$ \\
\hline Total & $20 \%$ & $45 \%$ & $13 \%$ & $78 \%$ \\
\hline
\end{tabular}

Table 4. Percentage of participants' department and gender (teachers)

\begin{tabular}{|l|c|c|c|}
\hline \multicolumn{1}{|c|}{ Department } & Female & Male & Total \\
\hline Arts \& Humanities & $6 \%$ & $9 \%$ & $15 \%$ \\
\hline Social Sciences & $2 \%$ & $0 \%$ & $2 \%$ \\
\hline Sciences & $2 \%$ & $3 \%$ & $5 \%$ \\
\hline Total & $10 \%$ & $12 \%$ & $22 \%$ \\
\hline
\end{tabular}

Table 5. Percentage of participants' institute type and location (teachers)

\begin{tabular}{|c|c|c|c|c|}
\hline \begin{tabular}{|ll} 
Type of Institution & Location \\
\end{tabular} & Public & Private & Semi-private & Total \\
\hline Urban & $13 \%$ & $5 \%$ & $2 \%$ & $20 \%$ \\
\hline Rural & $0 \%$ & $2 \%$ & $0 \%$ & $2 \%$ \\
\hline Total & $13 \%$ & $7 \%$ & $2 \%$ & $22 \%$ \\
\hline
\end{tabular}




\subsection{Tools used in pandemic}

The usefulness of technological tools during the COVID-19-19 pandemic is undeniable. Globally, many universities and higher education institutions have found it necessary to implement technological tools and platforms to continue the teachinglearning process. This section assesses the main platforms used by both students and teachers in the teaching and learning process.

In the case of students, Figure 3a shows the main technology platforms for education that were mostly used during the pandemic. Google Meet, Zoom and Microsoft Team stand out with $45.4 \%, 35.1 \%$ and $17.5 \%$ respectively. These mentioned technological tools, in the case of teachers, are the most useful in the teaching process as reported by the teachers, while Skype and Cisco Webex are practically unknown (see Figures $3 \mathrm{a}$ and $3 \mathrm{~b}$ ). These results are consistent for both students and teachers when considering the user rating of these tools (see Table 6 and Table 7). On the other hand, only $38.1 \%$ of students are unaware that the main technological platforms used during pandemic teaching are based on artificial intelligence.

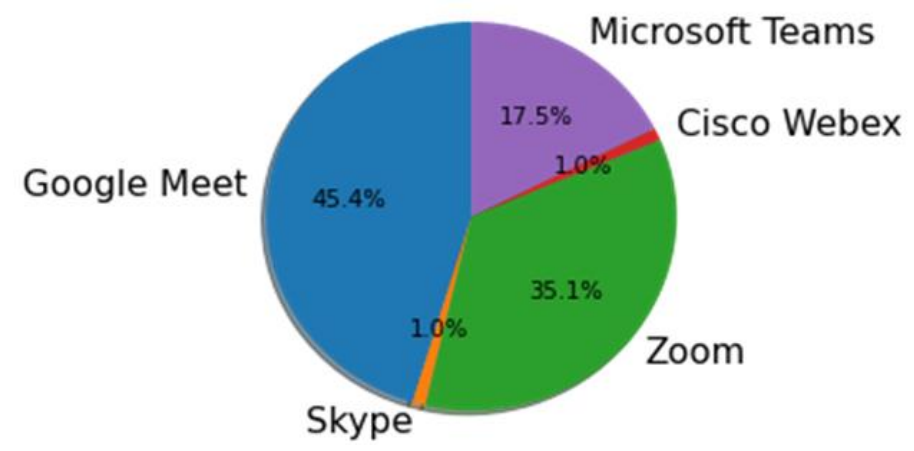

(a) Main Tools Used on Pandemic by Students

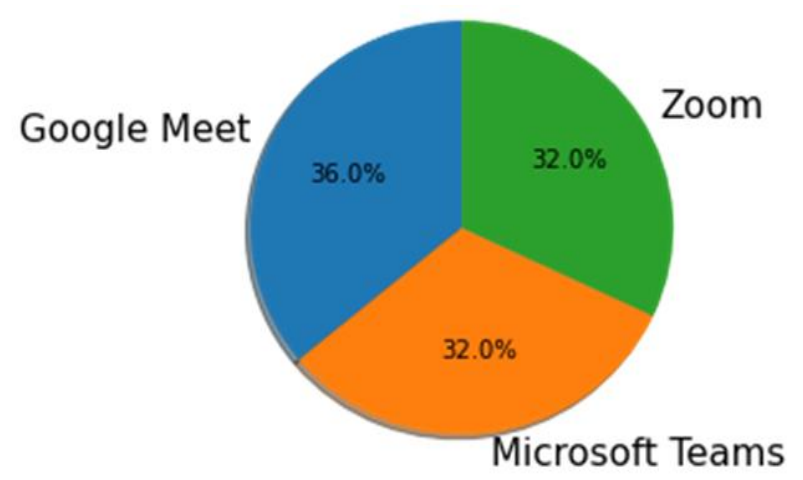

(b) Main Tools Used on Pandemic by Students

Fig. 3. Main tools used in Pandemic in the current study for (a) students and (b) teachers, from different higher education institutions in India. 
Table 6. Technology platforms mostly used for education during the pandemic

\begin{tabular}{|c|c|c|c|c|c|c|}
\hline Tools Rate & 1 & 2 & 3 & 4 & 5 & Total \\
\hline Cisco Webex & $0 \%$ & $0 \%$ & $0 \%$ & $0 \%$ & $1 \%$ & $1 \%$ \\
\hline Google Meet & $1 \%$ & $2.1 \%$ & $19.6 \%$ & $20.6 \%$ & $2.1 \%$ & $45.4 \%$ \\
\hline Microsoft Teams & $0 \%$ & $0 \%$ & $3.1 \%$ & $10.3 \%$ & $4.1 \%$ & $17.5 \%$ \\
\hline Skype & $0 \%$ & $0 \%$ & $1 \%$ & $0 \%$ & $0 \%$ & $1 \%$ \\
\hline Zoom & $3.1 \%$ & $1 \%$ & $18.6 \%$ & $9.3 \%$ & 3.1 & $35.1 \%$ \\
\hline Total & $4.1 \%$ & $3.1 \%$ & $42.3 \%$ & $40.2 \%$ & $10.3 \%$ & $100 \%$ \\
\hline
\end{tabular}

Table 7. Technology platforms used during the pandemic for teaching and unaware by students' unawareness about them being based on AI

\begin{tabular}{|c|c|c|c|}
\hline $\begin{array}{|ll|}\text { Tools } & \text { AI Platform } \\
\end{array}$ & No & Yes & Total \\
\hline Cisco Webex & $0 \%$ & $1 \%$ & $1 \%$ \\
\hline Google Meet & $18.6 \%$ & $26.8 \%$ & $45.4 \%$ \\
\hline Microsoft Teams & $6.2 \%$ & $11.3 \%$ & $17.5 \%$ \\
\hline Skype & $0 \%$ & $1 \%$ & $1 \%$ \\
\hline Zoom & $13.4 \%$ & $21.6 \%$ & $35.1 \%$ \\
\hline Total & $38.1 \%$ & $61.9 \%$ & $100 \%$ \\
\hline
\end{tabular}

\subsection{Tools to improve learning}

The main question that appeared regarding the usefulness of information technologies and teaching platforms focuses directly on academic performance. Likewise, it is also important to assess the students' preference regarding the teaching methods used, i.e. traditional, online, hybrid (traditional + online). Contrasting both questions, the results are shown in Figure 4, Table 8 and Table 9 are quite interesting. $21.6 \%$ of the students (12\% of the teachers) prefer traditional education, yet more than $50 \%$ of this group have improved their academic performance (12.4\% of the total). In the case of online teaching, only $6.2 \%$ of students ( $4 \%$ of the teachers) prefer it, of which more than $80 \%$ have improved their performance (5.2\% of the total). Finally, of the $72.2 \%$ of students ( $72 \%$ of the teachers) who prefer a hybrid teaching method, more than $67 \%$ have improved their academic performance ( $48.5 \%$ of the total). Focusing on the mode of assessment, $70.1 \%$ of students prefer to be assessed traditionally, regardless of the preferred teaching method (see Table 7). This result may indicate a loss of confidence in the criteria used for assessment as well as possible errors due to the use of technology when assessing. This attitude of showing preference in the traditional mode of assessment may be linked to various factors such as connectivity issues, network problem, socio-economic factors, audio or webcam problem among others. This, in a way, also shows the rigid mentality to change which may have been developed due to other environmental and/or contextual factors. 
(a) DID THE TOOLS IMPROVE LEARNING?

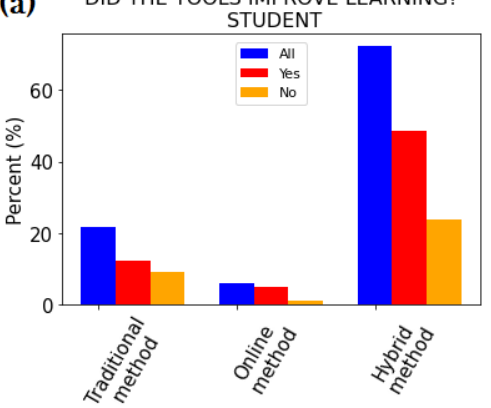

(b) DID THE TOOLS IMPROVE LEARNING?
FACULTY

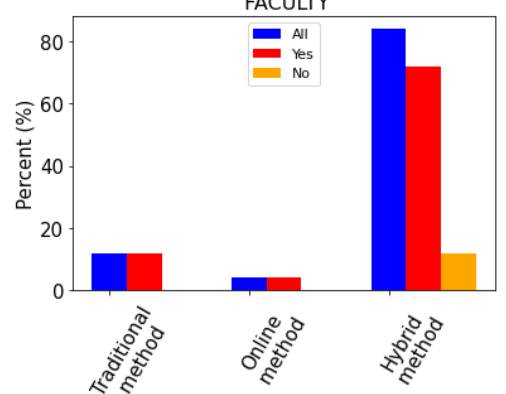

Fig. 4. Contrasting of academic performance and preference regarding the teaching methods used (traditional, online, and hybrid) for (a) students and (b) teachers.

Table 8. Students' response to teaching method and learning improvement during the pandemic

\begin{tabular}{|l|c|c|c|}
\hline Teaching method & Nearning improvement & Yes & Total \\
\hline Traditional & $9.3 \%$ & $12.4 \%$ & $21.6 \%$ \\
\hline Online & $1 \%$ & $5.2 \%$ & $6.2 \%$ \\
\hline Hybrid & $23.7 \%$ & $48.5 \%$ & $72.2 \%$ \\
\hline Total & $34 \%$ & $66 \%$ & $100 \%$ \\
\hline
\end{tabular}

Table 9. Teachers' response to teaching method and learning improvement during the pandemic

\begin{tabular}{|l|c|c|c|}
\hline Learning improvement & No & Yes & Total \\
\hline Traditional & $0 \%$ & $12 \%$ & $12 \%$ \\
\hline Online & $0 \%$ & $4 \%$ & $4 \%$ \\
\hline Hybrid & $12 \%$ & $72 \%$ & $84 \%$ \\
\hline Total & $12 \%$ & $88 \%$ & $100 \%$ \\
\hline
\end{tabular}

\subsection{Mode and type of learning}

One of the important factors in student performance is related to the learning type they receive. In the present work, the following types of teaching have been considered:

a) Standardized, which aims at standardizing contents and methods without considering the particular needs of each student.

b) Collaborative, focused on the students' strengths in order to increase and facilitate the acquisition of knowledge.

c) Personalised, which is adjusted to the strengths, needs, abilities and interests of each student.

Concerning the above, the results in Table 10 do not show a strong preference for any of the teaching types (standardized $35.1 \%$, collaborative $25.8 \%$, personalised $39.2 \%$ ). However, when the teaching method (traditional, online, hybrid) is consid- 
ered together, the preference for hybrid teaching stands out, both for the learning type method personalised $(29.9 \%)$, standardized $(21.6 \%)$ and collaborative $(20.6 \%)$.

Table 10. Students' response to teaching method and learning type.

\begin{tabular}{|l|c|c|c|c|}
\hline Leaching method & Standardized & Collaborative & Personalized & \multirow{2}{*}{ Total } \\
\hline Traditional & $10.3 \%$ & $3.1 \%$ & $8.2 \%$ & $21.6 \%$ \\
\hline Online & $3.1 \%$ & $2.1 \%$ & $1 \%$ & $6.2 \%$ \\
\hline Hybrid & $21.6 \%$ & $20.6 \%$ & $29.9 \%$ & $72.2 \%$ \\
\hline Total & $35.1 \%$ & $25.8 \%$ & $39.2 \%$ & $100 \%$ \\
\hline
\end{tabular}

Finally, taking into account that around $80 \%$ of the students prefer a nontraditional teaching method (online and hybrid), it is important to know the response of the students whether the presence of a personal assistant to accompany and assist during the learning period is necessary. The results in Table 11 show that more than $88 \%$ of the students prefer to have a personal assistant during the learning period, with an equal preference for the type of teaching (standardized $32 \%$, collaborative $22.7 \%$, personalised $34 \%$ ).

Table 11. Students' preference for personal teaching assistant in the learning process with teaching type.

\begin{tabular}{|l|c|c|c|}
\hline Learning type & Teacher during learning & Yes & Total \\
\hline Standardized & $3.1 \%$ & $32 \%$ & $35.1 \%$ \\
\hline Collaborative & $3.1 \%$ & $22.7 \%$ & $25.8 \%$ \\
\hline Personalized & $5.2 \%$ & $34 \%$ & $39.2 \%$ \\
\hline Total & $11.3 \%$ & $88.7 \%$ & $100 \%$ \\
\hline
\end{tabular}

Additionally, a Chatbot was considered to fulfil the tasks of a personal assistant during the learning process. The results in this regard are very promising, with over $61 \%$ of students think or would consider the use of chatbots as a personal assistant as a good alternative (see Table 12), which may point to a valid alternative to consider and exploit to improve student performance.

Table 12. Students' preference for Chatbot as a personal teaching assistant in the learning process with teaching type.

\begin{tabular}{|l|c|c|c|c|}
\hline Thatbot as a teacher & Standardized & Collaborative & Personalized & Total \\
\hline No & $17.5 \%$ & $12.4 \%$ & $8.2 \%$ & $38.1 \%$ \\
\hline Yes & $5.2 \%$ & $4.1 \%$ & $5.2 \%$ & $14.5 \%$ \\
\hline Maybe & $12.4 \%$ & $9.3 \%$ & $25.7 \%$ & $47.4 \%$ \\
\hline Total & $35.1 \%$ & $25.8 \%$ & $39.1 \%$ & $100 \%$ \\
\hline
\end{tabular}

The above results suggest a great opportunity to implement a hybrid education method with the characteristics proposed in the research. The hybrid education method would lead to better learning performance in the classroom and at the same time allow the use of the available technological tools effectively and efficiently. 


\section{Conclusions}

Huba and Freed [28] mention that the transition to a hybrid classroom often necessitates a shift from teacher-centred to learner-centred methods and techniques. The current quantitative study is a learner-centred approach wherein a hybrid force model is proposed by analysing the challenges and opportunities in online education and implementation of technological tools in Indian universities during the pandemic. The proposed model considers the learner as a system of study and talks about the amalgamation of knowledge, human force (teacher) and technological force for better online learning opportunities and experience. The model is a cyclical one in which the findings and the feedback generated in each cycle would help in the tasks of planning and organizing the didactic content according to the feedback and diversity of each student. The empirical study validated the proposed model through an online survey from students and teachers of the higher education institutes of India. Google Meet, Zoom, and Microsoft Team were the main online platform used for imparting the classes. Likewise, almost $80 \%$ of the students prefer a non-traditional teaching method (online and hybrid). The results indicate a reluctance to completely abandon traditional education and support for teachers. In this sense, they highlight that more than $88 \%$ of students prefer to have a personal assistant during the learning period, and more than $60 \%$ of them are open to considering AI-based tools, such as a chatbot, as an assistant during the learning period. Finally, a hybrid education model suggests a great opportunity to implement, leading to better learning performance in the classroom, with the help of knowledge, human force and the force provided by the technological tools available.

\section{$8 \quad$ References}

[1] U. Nations, "Pandemic disruption to learning is an opportunity to reimagine, revitalize education," [Online]. Available: https://news.un.org/en/story/2021/01/1082792. [Accessed $27012021]$.

[2] W. Zimmer, E. McTigue and N. Matsuda, "Development and validation of the teachers' digital learning identity survey," International Journal of Educational Research, vol. 105, p. 101717, 2021. https://doi.org/10.1016/j.ijer.2020.101717

[3] K. H. Mok, W. Xiong, G. Ke and J. Cheung, "Impact of COVID-19 pandemic on international higher education and student mobility: Student perspectives from mainland China and Hong Kong," International Journal of Educational Research, vol. 105, p. 101718, 2020. https://doi.org/10.1016/j.ijer.2020.101718

[4] S. Choudhury and S. Pattnaik, "Emerging themes in e-learning : A review from the stakeholder's perspective," Computers \& Education, vol. 144, 2019. https://doi.org/ 10.1016/j.compedu.2019.103657

[5] K. Upadhyaya and D. Mallik, "E-Learning as a Socio-Technical System: An Insight into Factors Influencing its Effectiveness," Business Perspectives and Research, vol. 2, pp. 112, 2013. https://doi.org/10.1177/2278533720130101

[6] K. Saichaie, "Blended, Flipped, and Hybrid Learning: Definitions, Developments, and Directions," New Directions for Teaching and Learning, vol. 2020, no. 164, pp. 95-104, 2020. https://doi.org/10.1002/t1.20428 
[7] B. Bogdandy, J. Tamas y Z. Toth, «Digital Transformation in Education during COVID19: a Case Study,» de 2020 11th IEEE International Conference on Cognitive Infocommunications (CogInfoCom), 2020. https://doi.org/10.1109/coginfocom50765.2020. $\underline{9237840}$

[8] C. Silander and M. Stigmar, "Individual growth or institutional development? Ideological perspectives on motives behind Swedish higher education teacher training," Higher Education, vol. 77, no. 2, pp. 265--281, 2019. https://doi.org/10.1007/s10734-018-0272-z

[9] M. Arora, L. M. Goyal, N. Chintalapudi and M. Mittal, "Factors affecting digital education during COVID-19: A statistical modeling approach," in 2020 5th International Conference on Computing, Communication and Security (ICCCS), 2020. https://doi.org/10.1109/icces 49678.2020 .9277370

[10] S. A. Aljawarneh, "Reviewing and exploring innovative ubiquitous learning tools in higher education," Journal of computing in higher education, vol. 32, no. 1, pp. 57-73, 2020. https://doi.org/10.1007/s12528-019-09207-0

[11] S. Caliskan, R. A. Kurbanov, R. I. Platonova, A. M. Ishmuradova, D. G. Vasbieva and I. V. Merenkova, "Lecturers Views of Online Instructors about Distance Education and Adobe Connect.," International Journal of Emerging Technologies in Learning,, vol. 15, no. 23, pp. 145-157, 2020. https://doi.org/10.3991/ijet.v15i23.18807

[12] D. A. Oktavianto, S. Sumarmi, S. Utaya and T. Didik, "Blended Learning Integrated Fieldwork on Fundamentals of Geology Learning During the Covid-19 Pandemic.," International Journal of Emerging Technologies in Learning,, vol. 16, no. 07, pp. 90-104, 2021. https://doi.org/10.3991/ijet.v16i07.21213

[13] N. M. Almusharraf and S. H. Khahro., "Students' Satisfaction with Online Learning Experiences During the COVID-19 Pandemic," International Journal of Emerging Technologies in Learning,, vol. 15, no. 21, pp. 246-267, 2020. https://doi.org/10.3991/ ijet.v15i21.15647

[14] S. Popenici and S. Kerr, "Exploring the impact of artificial intelligence on teaching and learning in higher education," Research and Practice in Technology Enhanced Learning, vol. 12, p. 22, 2017. https://doi.org/10.1186/s41039-017-0062-8

[15] K. VanLehn, "The relative effectiveness of human tutoring, intelligent tutoring systems, and other tutoring systems," Educational Psychologist, vol. 46, no. 4, pp. 197--221, 2011. https://doi.org/10.1080/00461520.2011.611369

[16] K. Holstein, V. Aleven and N. Rummel, "A Conceptual Framework for Human--AI Hybrid Adaptivity in Education," in International Conference on Artificial Intelligence in Education, 2020. https://doi.org/10.1007/978-3-030-52237-7_20

[17] I. Sangapu, "Artificial Intelligence in Education-From a Teacher and a Student Perspective," Available at SSRN 3372914, 2018.

[18] S. Chatterjee and K. K. Bhattacharjee, "Adoption of artificial intelligence in higher education: A quantitative analysis using structural equation modelling," Education and Information Technologies, vol. 25, no. 5, pp. 3443--3463, 2020. https://doi.org/10.1007/ $\underline{\mathrm{s} 10639-020-10159-7}$

[19] V. Venkatesh, M. G. Morris, G. B. Davis and F. D. Davis, "User acceptance of information technology: Toward a unified view," MIS quarterly, pp. 425--478, 2003. https://doi.org/10.2307/30036540

[20] J. Zheng and S. Li, "What drives students' intention to use tablet computers: An extended technology acceptance model," International Journal of Educational Research, vol. 102, p. 101612, 2020. https://doi.org/10.1016/j.ijer.2020.101612

[21] O. Zawacki-Richter, V. Marín, M. Bond and F. Gouverneur, "Systematic review of research on artificial intelligence applications in higher education -where are the 
educators?," International Journal of Educational Technology in Higher Education, vol. 16, pp. 1-27, 2019. https://doi.org/10.1186/s41239-019-0171-0

[22] K. Hew, M. Lan, Y. Tang, C. Jia and C. K. Lo, "Where is the "theory" within the field of educational technology research?," British Journal of Educational Technology, vol. 50, pp. 956-971, 2019. https://doi.org/10.1111/bjet.12770

[23] A. Mittal, A. Mantri, U. Tandon and Y. K. Dwivedi, "A unified perspective on the adoption of online teaching in higher education during the COVID-19 pandemic," Information Discovery and Delivery, 2021. https://doi.org/10.1108/idd-09-2020-0114

[24] V. P. Gantasala, S. B. Gantasala, N. T. Al Tawil and P. Prasad, "Quality of learning experience, student satisfaction and perceived overall experience in the COVID-19 context," Journal of Applied Research in Higher Education. https://doi.org/10.1108/jarhe$\underline{12-2020-0440}$

[25] K. Syed, R. Kandakatla, R. I. Yadav, R. Himasagarika and others, "Responding to COVID-19 and Transitioning to Online Learning: Evaluation of an Institution wide Capacity Building Efforts on Technology-Enhanced Learning," Journal of Engineering Education Transformations, vol. 34, pp. 620-627, 2021. https://doi.org/10.16920/jeet/ 2021/v34i0/157232

[26] A. Sangwan, A. Sangwan and P. Punia, "Development and Validation of an Attitude Scale towards Online Teaching and Learning for Higher Education Teachers," Techtrends, pp. 19, 2020. https://doi.org/10.1007/s11528-020-00561-w

[27] S.-S. Liaw, H.-M. Huang and G.-D. Chen, "Surveying instructor and learner attitudes toward E-learning," Computers \& Education, vol. 49, pp. 1066-1080, 2007. https://doi.org /10.1016/j.compedu.2006.01.001

[28] M. Huba and J. Freed, Learner-Centered Assessment on College Campuses: Sifting the Focus from Teaching to Learning, Community College Journal of Research and Practice, 2000.

\section{Authors}

Dr Ranjeeva Ranjan is an Assistant Professor in the Department of Educational Foundations, Faculty of Education of Universidad Católica del Maule, Talca, Chile.

Dr J. L. López is working as Researcher at the Centre of Innovation in Applied Engineering of Universidad Católica del Maule in Talca, Chile.

Dr Kanhaiya Lal is Head of the Department of Computer Science and Engineering, Birla Institute of Technology, Patna Campus

Mr. Suraj Saxena has done Master of Technology (M.Tech.) from Birla Institute of Technology, Mesra.

Mr. Sanjeev Ranjan is doctoral candidate at Birla Institute of Technology, Mesra after obtaining M.Tech.

Article submitted 2021-04-17. Resubmitted 2021-05-16. Final acceptance 2021-05-17. Final version published as submitted by the authors. 